\title{
Sensitivity of Enhanced SRTM for Sea-Level Rise Variation on Egyptian Coasts
}

\author{
Alshimaa A. Hussien 1,*, Mohamed Gomaa M. Mohamed², Pasent H. A. Yousef ${ }^{3}$, Mohamed R. Hagag ${ }^{3}$, \\ Tarek Abou El Seoud ${ }^{3}$ \\ ${ }^{1}$ Survey Research Institute, National Water Research Center, Giza, Egypt \\ ${ }^{2}$ Public Works Department, Faculty of Engineering, Cairo University, Giza, Egypt \\ ${ }^{3}$ Environmental Planning and Infrastructure Department, Faculty of Urban and Regional Planning, Cairo University, Giza, Egypt
}

Received March 24, 2021; Revised April 19, 2021; Accepted May 28, 2021

\section{Cite This Paper in the following Citation Styles}

(a): [1] Alshimaa A. Hussien, Mohamed Gomaa M. Mohamed, Pasent H. A. Yousef, Mohamed R. Hagag, Tarek Abou El Seoud, "Sensitivity of Enhanced SRTM for Sea-Level Rise Variation on Egyptian Coasts," Civil Engineering and Architecture, Vol. 9, No. 3, pp. 958 - 968, 2021. DOI: 10.13189/cea.2021.090337.

(b): Alshimaa A. Hussien, Mohamed Gomaa M. Mohamed, Pasent H. A. Yousef, Mohamed R. Hagag, Tarek Abou El Seoud (2021). Sensitivity of Enhanced SRTM for Sea-Level Rise Variation on Egyptian Coasts. Civil Engineering and Architecture, 9(3), 958 - 968. DOI: 10.13189/cea.2021.090337.

Copyright $\odot 2021$ by authors, all rights reserved. Authors agree that this article remains permanently open access under the terms of the Creative Commons Attribution License 4.0 International License

\begin{abstract}
The accuracy of digital elevation models (DEMs) is very critical to planning adaptation strategies for coastal areas under changing scenarios of global climate and sea-level rise. This research assesses the accuracy of the interferometric DEM from the SRTM mission as it is one of the free available DEMs that have been widely used in many applications. The SRTM model is enhanced using the best fit global geoid model for Egypt instead of EGM96 and by applying a mathematical scale factor formula. This research aims to obtain a higher vertical accuracy of the SRTM model that achieves the requirements for coastal inundation studies with minimum field measurement data. The methodology approach consists of three phases. In the first phase, the enhancement scale factor formulas were derived using uniformly distributed ground control points (GCPs) at two different terrains data in Egypt. The second phase contains the evaluation and validation process. It was observed that the enhanced accuracy achieved ranged from $45 \%$ to $60 \%$ based on the type of terrains. In the last phase, the sensitivity of these DEMs to sea-level projections using the recent available local tide gauge data was analyzed. It is recommended to investigate this method approach to determine the optimal size and distribution of reference ground control points needed to adjust various free open DEMs of low vertical accuracy for further studies and other applications.
\end{abstract}

Keywords SRTM, Vertical Accuracy, Coastal
Inundation, Scale Formula, Enhancement, Tide Gauge

\section{Introduction}

Nowadays, planning, development, and risk management along the Egyptian coasts need to conduct several studies including topography, water resources, climate change, and sea-level rise $[1,2]$. Sea level rise (SLR) currently poses a significant threat to coastal areas in Egypt and around the whole world. During the period 1901-2010, the global mean sea level rose by 19 centimetres and it is very likely that the SLR will exceed the observed rate of $2.0 \mathrm{~mm} / \mathrm{year}$ during 1971-2010, with the rate of 8 to $16 \mathrm{~mm} / \mathrm{year}$ during 2081-2100[3]. The existence of a reliable and precise digital elevation model (DEM) is greatly required to support the decision-makers for planning the needed adaptation strategies to sea level rise. A Digital Elevation Model (DEM) is referred to as a digital representation of the topographic surface in three dimensions with height (elevation) described above mean sea level. Traditionally, A DEM can be obtained using different sources such as Terrestrial survey, Aerial photo, LIDAR, and Satellite survey. Terrestrial survey uses both the conventional and modern surveying instruments to produce the DEM such as Global Navigation Satellite 
System (GNSS), Total Stations, and leveling. Although this method gives reasonably accurate results, the method is time-consuming and less efficient when applied to an area which is not easily accessible. The elevation accuracy of DEM obtained using the sources like LIDAR and aerial survey are good and cover a large area compared to Terrestrial survey. But it is restricted to do aerial surveys in some countries because of security reasons and limited resources of data collection [4,5]. There is now a revolution in the use of satellite survey data to overcome many of the obstacles facing traditional surveying methods, as there is a future promising that higher accuracy DEMs will be freely available for the globe.

Currently, numerous freely open-access global DEMs with large global coverage are available, for example, the Advanced Space borne Thermal Emission and Reflection Radiometer (ASTER), the Shuttle Radar Topography Mission (SRTM), the Global Multi-resolution Terrain Elevation Data 2010 (GMTED2010), the Global 30 Arc-Second Elevation (GTOPO30) and EarthEnv-DEM90 digital elevation models [6]. ASTER and SRTM are the two most commonly Global DEMs that are addressed in several studies. ASTER is a cooperative effort between Japan's Ministry of Economy, Trade, and Industry (METI) and U.S. National Aeronautics and Space Administration (NASA) that was released in October 2011. The characteristics of ASTER are a spatial resolution of 1 arc $\sec (\sim 30 \mathrm{~m})$ and a height accuracy of about $17 \mathrm{~m}[7,8,9]$. On the other hand, SRTM is a joint effort of NASA, the National Geospatial- Intelligence Agency (NGA), the German Aerospace Center (DLR), and the Italian Space Agency (ASI). The recent version (4.1) of SRTM with a spatial resolution of $1 \mathrm{arc} \sec (30 \mathrm{~m})$ and around $16 \mathrm{~m}$ of vertical height accuracy was released in September 2014 $[10,11,12]$. EarthEnv-DEM90 with a spatial resolution of $3 \operatorname{arc} \sec (\sim 90 \mathrm{~m})$ is a compilation dataset that is merged from ASTER GDEM v2 and SRTM v4.1[13]. GMTED2010 is developed by a collaborative effort of the U.S. Geological Survey (USGS) and the NGA. GMTED2010 has been produced at three separate spatial resolutions: 7.5 arc sec $(\sim 250 \mathrm{~m}), 15 \operatorname{arc} \sec (\sim 500 \mathrm{~m})$, and $30 \operatorname{arc} \sec (\sim 1 \mathrm{~km})[14,15]$. Also, GTOPO30 is produced by the staff at the USGS Center for Earth Resources Observation and Science with a horizontal cell size of $30 \operatorname{arc~sec}(\sim 1 \mathrm{~km})$ and was obtained from several rasters and vector sources of topographic information [16]. These freely DEMs differ in the data resolution and accuracy, according to the technology of data acquisition and the methodology of processing concerning a particular terrain and land cover type. The positional and attributive accuracy of these DEMs is often unknown and non-uniform within each dataset $[17,18]$.

On the other hand, the height supplied by open-source data is related to the reference ellipsoid which is called ellipsoidal height (h). However, the height-related to an equipotential surface of the terrestrial gravity field is the most important for DEM generation. This height is called the orthometric height $(\mathrm{H})$. The relation between these two heights is the geoid undulation $(\mathrm{N})$, i.e., for obtaining orthometric height, based on the ellipsoidal height. It is necessary to understand the geoid undulation. The geoid undulation varies from one site to another. The Earth Gravitational Models (EGM96 and EGM2008) are some of the global geo-potential models that are used to have geoid undulation the orthometric height $[19,20]$. The conversion of ellipsoidal height (h) of these DEMs into orthometric height $(\mathrm{H})$ is fundamental in most geoscience and engineering applications. This conversion requires the geoid undulation (N) related to World Geodetic System (WGS84) ellipsoid by using the simple mathematical relation $\mathrm{H}=\mathrm{h}-\mathrm{N}[20,21]$.

In fact, no official precise local DEM for Egypt is published yet. So, using the free source data requires accordingly to examine the qualities and assesses the accuracy before attempting any data extraction from these freely DEM and the Global Geopotential Model (GGM) products. Rabah et al. [22] have checked the accuracy of three types of global DEMs (namely SRTM 1, SRTM 3, and ASTER) using precise GPS/leveling control points. The results showed that the most accurate one was the SRTM 1 that produced a mean height difference and standard deviations equal 2.89 and \pm 8.65 m respectively. El-Quilish et al.[23] have compared eight types of global DEMs in the Nile delta region including (EarthEnv-D90, SRTM 1, SRTM 3, ASTER, GMTED2010, and GTOPO30) using 416 GPS/leveling control points. They have introduced a statistical measure for DEMs accuracy evaluation called the reliability Index, which is based on the weighted average mean concept. The results showed that in the Nile delta region, EarthEnv-D90 and SRTM models have a high-reliability Index. Furthermore, Al-Krargy et al.[24] investigated three types of global DEMs (namely ASTER, SRTM 3 arc-second, and GTOPO30) and compared seven GGM including (EGM2008, and EGM96) over precise local gravity and GPS/Leveling data. The results showed that the SRTM 3 DEM produces a mean standard deviation of $\pm 4.3 \mathrm{~m}$, using 1227 observed orthometric heights control points in Egypt. As well, it has been indicated that the EGM2008 is the most precise global model, as it produces a mean standard deviation of geoid undulation differences which equals \pm $0.23 \mathrm{~m}$ using observed $1074 \mathrm{GPS} /$ Leveling stations.

Most of the Egyptian coastal lands are becoming vulnerable to inundation as their elevation will likely be below the projected sea-level rise under the impact of global warming and climate change [25]. From the previous studies, most of these recent studies investigated the assessment analysis and comparisons between different DEMs, but did not put forwards methods of accuracy enhancement for specific applications, especially in Egypt. The accuracy of DEM data are critical regarding the results of coastal flood risk assessments, because topographic data 
are the most important factor in determining the extent of flooding and therefore the accuracy of flood maps. Especially in low-lying coastal zones, the simulation of flood extents was found to be very sensitive to the terrain representation [26,27]. Therefore, this research aims to obtain the highest possible vertical accuracy of SRTM that achieve the requirements for coastal inundation risk studies with minimum volume of field measurements data. In this paper, an enhanced SRTM model is introduced by using the best fit global geoid model for Egypt instead of EGM96. The enhancement was completed by applying a scale factor formula that were derived mathematically by using actual field measurements of uniformly distributed ground control points along the study area. Then, the improved accuracy was evaluated at the two study areas of different types of terrain surfaces e.g., flat terrain and hilly one. This method approach was validated by using high precession local DEMs and the Sensitivity of these DEMs to sea level projections was statistically analysed.

\section{Study Areas and Available Data}

Egypt has coastlines about1550 $\mathrm{km}$ on the Mediterranean Sea on the north side, including the River Nile in the middle. However, on the east side, Egypt's Red Sea coastline is about $1705 \mathrm{~km}$ [28]. The Nile Delta is the delta formed in Lower Egypt where the Nile River spreads out and drains into the Mediterranean Sea. From west to east, it covers around $240 \mathrm{~km}$ of coastline. Two case studies were selected to achieve the purpose of this research. The study area (1) of around $200 \mathrm{~km}$ long and 500 $\mathrm{m}$ wide was selected at the Nile Delta coast. This area has the advantage of being a flat terrain. The mainland used in this area is agriculture. Fig. 1 represents the location of the Delta study area. The green-colored points represent the reference (GCPs) that were measured and processed using the GNSS instrument and Leveling. The Red-colored points along the whole study area are the grid of points measured using the GNSS post-processing kinematic (PPK) technique with an observation interval of 5 seconds. These points will be used for local DEM creation and validation purposes.

The second study area is along the Red Sea coast. It is about $194 \mathrm{~km}$ long and $500 \mathrm{~m}$ wide as well. This area was selected as the case study of hilly terrain and it is considered as a worldwide known touristic zone. The location of the study area (2) and the used land surveying data is shown in Fig.2.
Generally, the topographic and tidal Data are the two main types of data that were used in this research as follows:

- Leveling measurements of 50 GCPs on the Nile Delta coast and 46 GCPs on the Red Sea coast were used. They were distributed uniformly about $5 \mathrm{~km}$ spacing parallel to the coastlines and observed by using the precise level instrument. These high-precision 96 GCPs were obtained by using the international standards and specifications by the survey research institute in Egypt.

- Two local DEMs surfaces were generated with $30 \mathrm{~m}$ cell size using GIS application. They were created based on land surveying data which contains around 25778 Grid points distributed from Rashid at $30.38^{\circ} \mathrm{E}$ to Brullus at $30.96^{\circ} \mathrm{E}$ along the Nile delta coast (refer to Fig.1) and about 19887 Grid points with around $60 \mathrm{~km}$ between $26.2^{\circ} \mathrm{N}$ and $25.8^{\circ} \mathrm{N}$ along the red sea coast (refer to Fig.2). These points were collected and processed by GNSS instruments, Dual Frequency GNSS Receivers, using the kinematic GNSS technique and adjusted to the local vertical datum by the survey research institute in Egypt.

- On the other hand, a Free source of DEM data with global 1-arcsecond (30-m) SRTM elevation data for the study areas was downloaded from Earth Explorer (http://earthexplorer. usgs.gov) website of the United States Geological Survey. This data was processed and projected to the Universal Transverse Mercator (UTM) coordinate system of zone 36.

- The available nearest tide gauge stations for the two different study areas are at Alexandria and Safaga respectively. These stations were established by the Survey Research Institute (SRI) of the National Water Research Center (NWRC) cooperated with the Egyptian Navy Hydrographic Department (ENHD). Table1 presents the locations and characteristics of the collected tide gauge datasets at these stations.

Table 1. Available Tide Datasets in the research areas along the Egyptian coasts

\begin{tabular}{|c|c|c|}
\hline \multirow{2}{*}{ Station } & \multicolumn{2}{|c|}{ Period( 2008-2018) } \\
\cline { 2 - 3 } & \multicolumn{2}{|c|}{ pressure-type devices } \\
\cline { 2 - 3 } & \multicolumn{2}{|c|}{ Location-coordinates } \\
\cline { 2 - 3 } & $31^{\circ} 11^{\prime} 55.91 "$ & E \\
\hline Alex. & $26^{\circ} 44^{\prime} 56.93^{\prime \prime}$ & $33^{\circ} 52^{\prime} 2.23^{\prime \prime} 04.58^{\prime \prime}$ \\
\hline Safaga & \multicolumn{2}{|c}{} \\
\hline
\end{tabular}




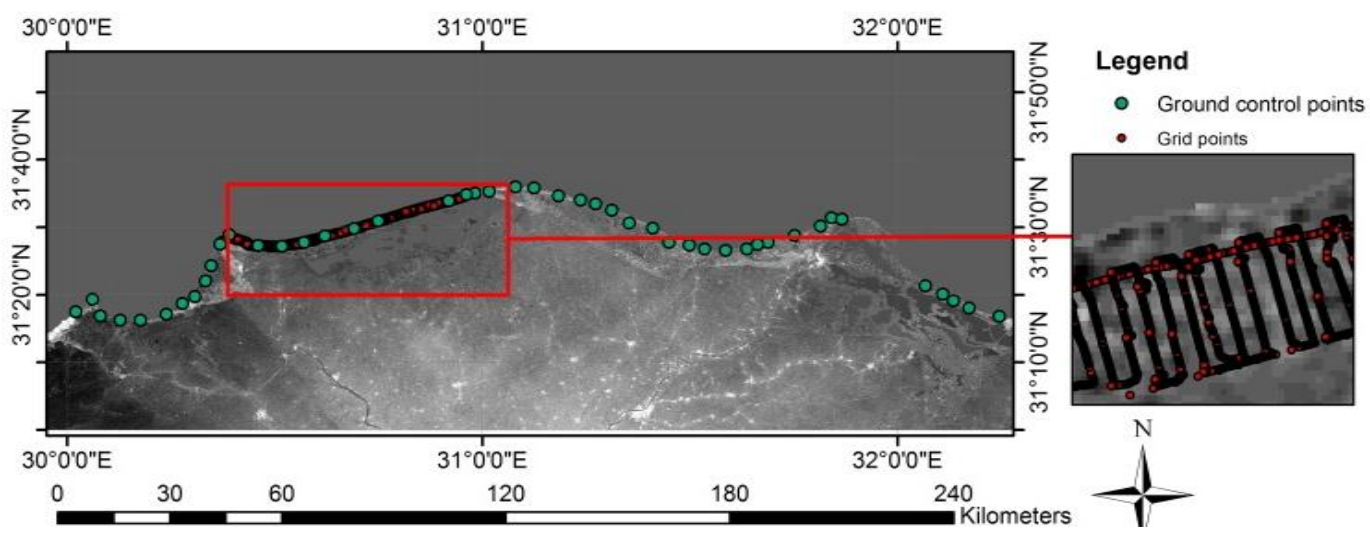

Figure 1. location of study area (1) and the reference GCPs at Nile delta coast

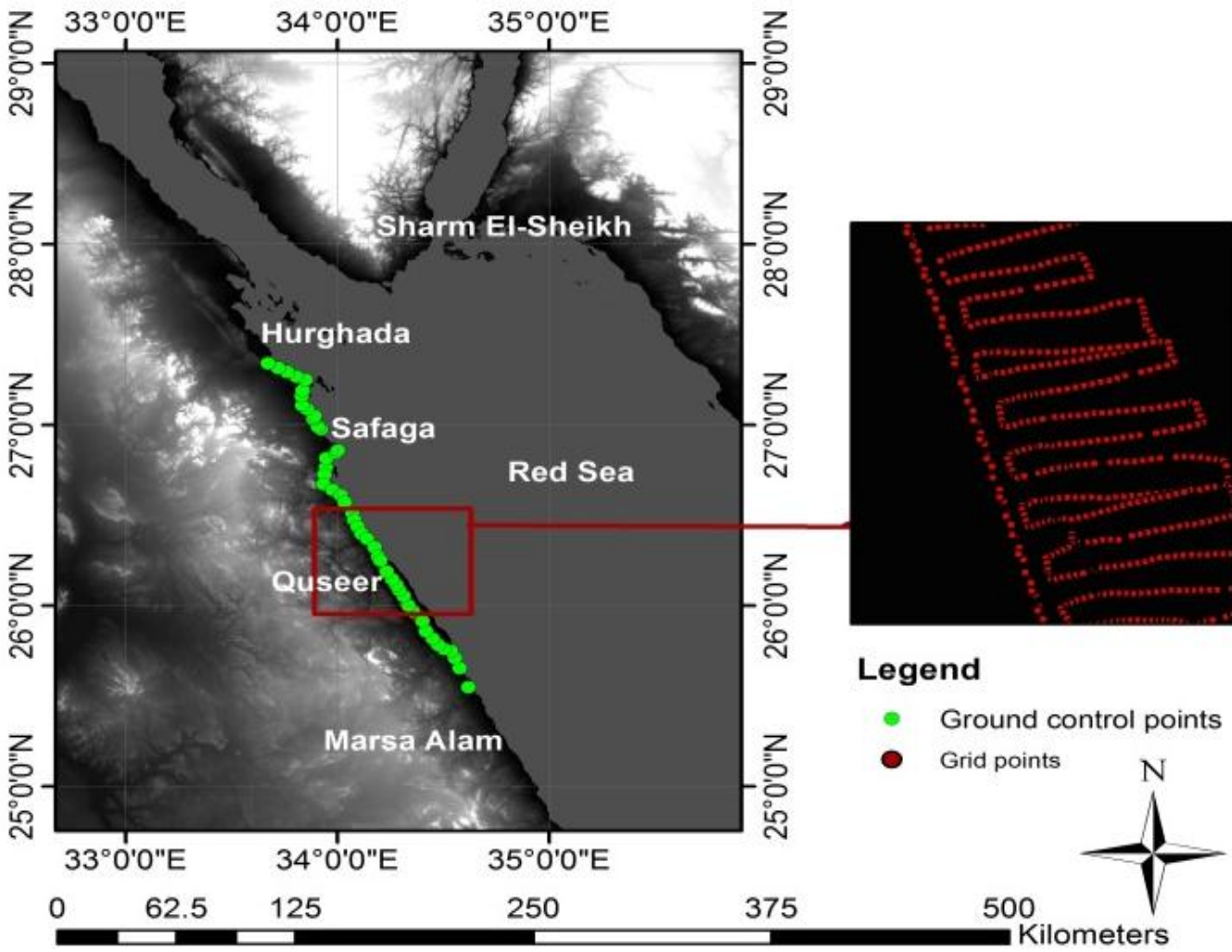

Figure 2. Location of study area (2) and the reference GCPs at Red sea coast

\section{Methodology}

The methodology described to achieve the objective of this paper is based on three main phases:

\section{The first phase: SRTM data enhancement}

The Horizontal datum of SRTM data is World Geodetic System (WGS 84). However, the vertical datum is Earth Gravitational Model (EGM96). To assess the quality of the SRTM data, several procedures were conducted. The 96 used reference ground control points are considered to be uniformly distributed parallel to the coastline at both study areas. The corresponding values of these points from SRTM DEM were extracted under GIS Environment by using bilinear interpolation. Then, the enhancement introduced approach was applied using these GCPs based on two steps. In the first step, the Earth Gravitational Models EGM96 which is included in SRTM was replaced to EGM2008. EGM2008 was selected as it was proven to be the most precise global model for Egypt referring to the previously mentioned studies.

The geoid heights from EGM96 and EGM2008 were computed at each location using NIMA EGM96 calculator (ver1.0) and Altrans. EGM2008 calculator, respectively. These software applications compute the accurate geoid undulation values which are used in the conversion of SRTM orthometric to ellipsoidal heights and vice versa. In the second step, a mathematical scale factor formula for each study area using the GCPs and the extracted corresponding elevation points from SRTM is derived. At 
both different terrains study areas, the simple scale factor formulas using a linear transformation method were used to achieve better agreement with the reference ground control points.

$$
\mathrm{Z}_{0}=\mathrm{a} \cdot\left(\mathrm{Z}_{\mathrm{m}}+\mathrm{N}_{\text {EGM96 }}-\mathrm{N}_{\text {EGM2008 }}\right)+\mathrm{b}
$$

Where $\mathbf{Z}_{\mathbf{0}}$ is the observed elevation at reference GCPs, $\mathbf{Z}_{\mathrm{m}}$ is the Model's elevation from SRTM. $\mathbf{N}_{\text {EGM96 }}$ and $\mathbf{N}$ EGM2008 are the geoid undulation values from EGM96 and EGM2008 respectively. The values of $\mathbf{a}$ and $\mathbf{b}$ are the estimated transformation parameters.

\section{The second phase: Enhancement evaluation and validation by statistical analysis}

The values of the actual levels of the 96 used reference points were compared with the data extracted from SRTM DEMs and after applying the scaling formulas at the same exact control point locations. The evaluation of the vertical accuracy for these points from DEMs is performed by computing the vertical Root-Mean-Square-Error (RMSE) and mean error (ME). RMSE measures the difference between the values of the DEM elevations and the values of reference GCPs elevations. These individual point differences are also called residuals. ME lets us know whether the set of measurements higher or lower than the true values RMSE and ME may be estimated by the following equations [29]:

$$
\begin{aligned}
M E & =\frac{1}{n} \sum_{i=1}^{n}\left(E_{o}-E_{m}\right) \\
\text { RMSE } & =\sqrt{\frac{1}{n} \sum_{i=1}^{n}\left(E_{o}-E_{m}\right)^{2}}
\end{aligned}
$$

Where $\mathbf{E}_{\mathbf{0}}$ is the observed elevation, $\mathbf{E}_{\mathbf{m}}$ is the model's elevation and $\mathbf{n}$ is the number of tested elevation points.

The validation of the accuracy enhancement approach for the free available SRTM DEM was done by using the same scaling mathematical formulas derived from the reference GCPs in phase1. These simple scaling formulas were applied to the whole raster surface of the SRTM DEM at both study areas after the conversion to the global model of EGM2008. The raster of the gravity models of EGM2008 and EGM96 were downloaded from International Centre for Global Earth Models (ICGEM) to be used in the conversions process of SRTM [30]. The resulted scaled SRTM model surfaces have been compared with LDEMs at both study areas. The RMSE was computed by subtracting SRTM DEMs from the accurate LDEMs and producing new raster DEMs showing all the elevation differences (DOD). All these calculations related to the DEMs raster were done using the calculate statistics and raster math tool in GIS application.

\section{The third phase: Sea Level rise Analysis}

Sea level projections were based on analysing hourly, monthly, and annual tide records at Alexandria (city located on the Mediterranean Sea) and Safaga (city located on the Red Sea). Linear regression has been carried out based on this data to compute the rising rates of sea level at the two tide gauge sites. Then, the Sensitivity analysis of DEMs to sea level projections was performed using GIS application to determine the areas that are topographically lower than the elevated water levels. The inundation extent and water depth on each DEM dataset for different SLR scenarios were studied taking in consideration to check hydrologic connectivity.

\section{Results and Discussion}

The statistics of the variation of elevations data from SRTM DEMs with the corresponding actual values from GCPs have appeared in Table 2 for the two study regions.

As appeared in the above table, the height variations values range from $0.90 \mathrm{~m}$ to $6.53 \mathrm{~m}$, with an average of 2.58 $\mathrm{m}$ and standard deviations equalling $\pm 1.19 \mathrm{~m}$ referring to the 50 GCPs used at the Nile Delta. Moreover, the height variations at the red sea area referring to the $46 \mathrm{GCPs}$ used are in the order of $31 \mathrm{~m}$ with an average of $6.69 \mathrm{~m}$ and standard deviations equalling $\pm 6.23 \mathrm{~m}$ (see Table 2 ). It can be realized that compared with the SRTM, the DEM after enhancement and scaling (Scale SRTM) produces the smallest differences with a standard deviation equalling \pm $0.18 \mathrm{~m}$ and $\pm 5.56 \mathrm{~m}$ at the Nile delta coast and the red sea coast study areas. Also, the error statistics at different terrains shows RMS error of $1.16 \mathrm{~m}$ and $2.76 \mathrm{~m}$ for the introduced enhanced SRTM. The figures showed that the RMS error was significantly decreased about $60 \%$ and $45 \%$ after enhancement and scaling of SRTM at the Nile Delta and the red sea coast study areas respectively (shown in Fig. 3). Generally, the RMS error of SRTM DEM's were clearly lower in plain regions like the Nile Delta coast compared to hilly regions like the red sea coast study area.

Table 2. Height variation in SRTM DEM's and GCPs for study areas along Egyptian coasts

\begin{tabular}{|c|c|c|c|c|c|c|}
\hline & \multicolumn{3}{|c|}{ Nile Delta coast } & \multicolumn{3}{c|}{ Red sea coast } \\
\hline Height & GCPs & SRTM & $\begin{array}{c}\text { scale- } \\
\text { SRTM }\end{array}$ & GCPs & SRTM & scale-SRTM \\
\hline Min & 0.90 & -5.00 & 2.13 & 1.13 & 0.00 & -1.56 \\
\hline Max & 6.53 & 9.00 & 3.07 & 32.21 & 35.00 & 24.45 \\
\hline Average & 2.58 & 1.78 & 2.58 & 6.69 & 10.54 & 6.69 \\
\hline St.Dev. & 1.19 & 2.72 & 0.18 & 6.23 & 7.50 & 5.56 \\
\hline
\end{tabular}




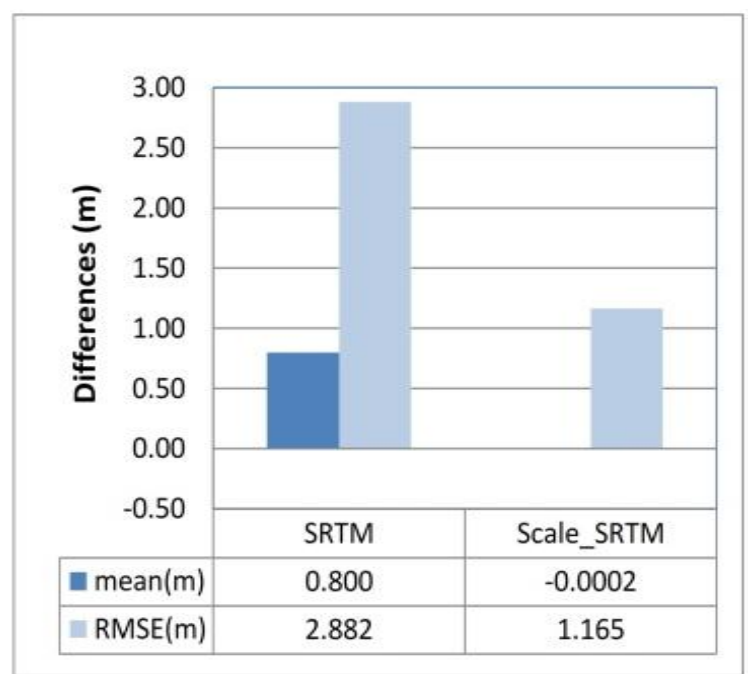

(a) Nile Delta coast study area (1)

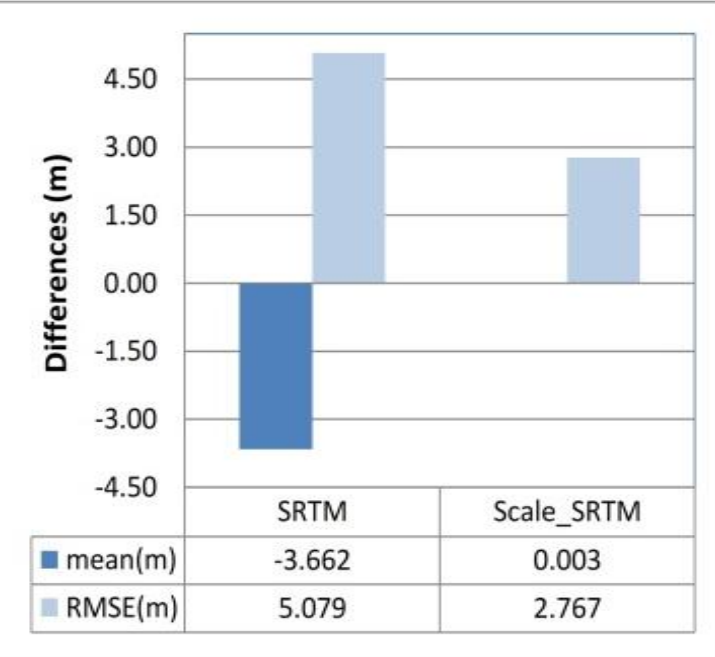

(b) Red sea coast study area (2)

Figure 3. Accuracy evaluation of SRTM models due to comparisons at independent tested control points for both study areas

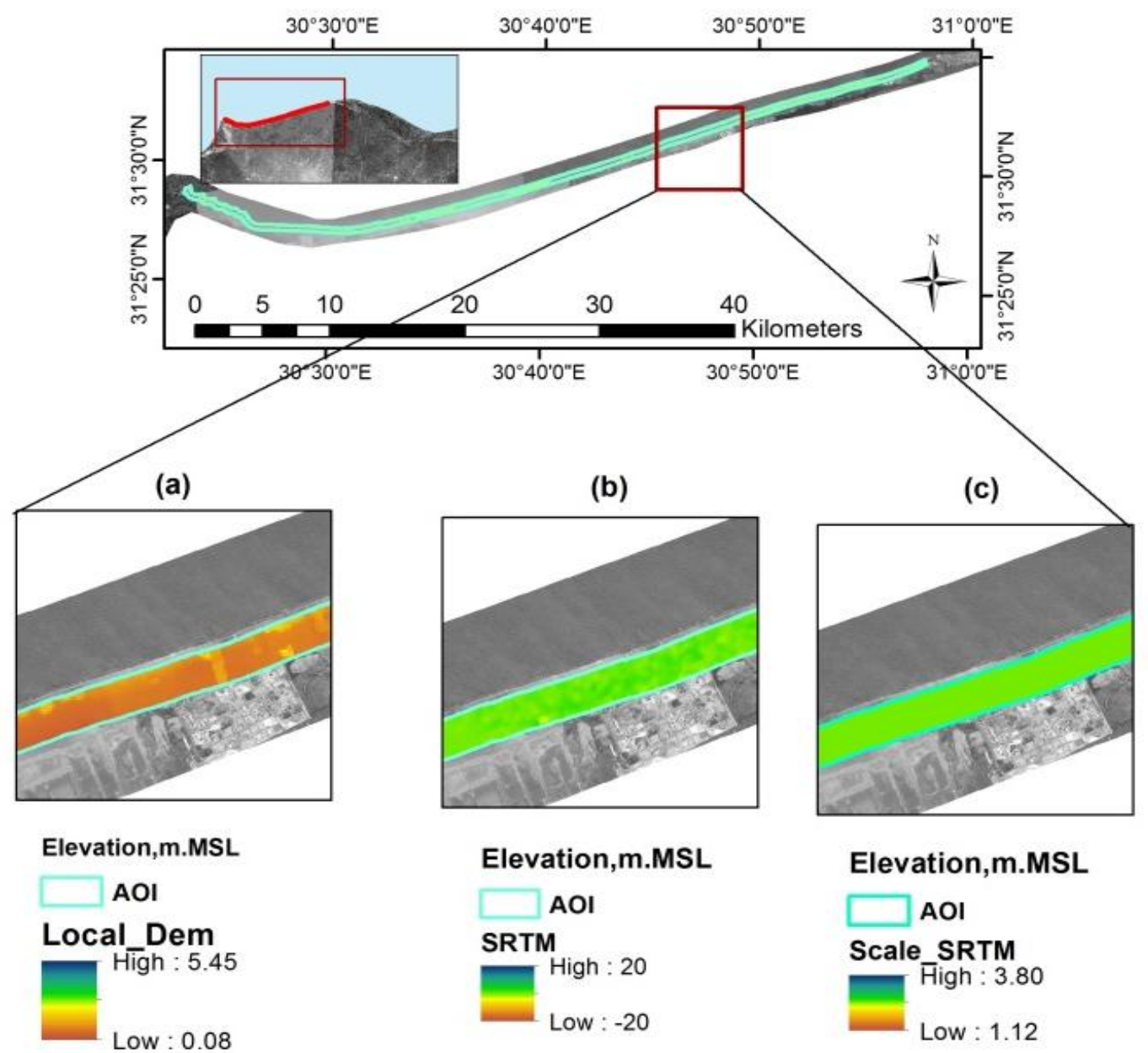

Figure 4. (a) Local DEM; (b) ) SRTM DEM; (c) Scale SRTM DEM for Nile Delta study area

In this section, the introduced methodology was validated by comparing DEMs raster with GIS application. The local DEMs (LDEMs) at two different terrains are considered as a reference to assess the vertical accuracy of SRTM after the enhancement by the same derived scaling formulas from GCPs in phase 1. The two references local
DEMs properties were described in section 2. Figures (4-7) highlighted the selected area of interest (AOI) and contained layout views in different scales for each DEM raster to show the surface of elevations for the (AOI) at each study area.

The local DEM in Fig. 4(a) for the Nile Delta study area 
showed variations in elevations from $+0.08 \mathrm{~m}$ to $+5.45 \mathrm{~m}$, while in Fig. 4(b) the variations in elevations were from -20 $\mathrm{m}$ to $+20 \mathrm{~m}$ for the SRTM. Fig. 4(c) showed the enhanced elevation of SRTM from $+1.12 \mathrm{~m}$ to $+3.80 \mathrm{~m}$ by applying EGM2008 and the scale factor formula derived using the 50 GCPs in the Nile Delta coast.

An analysis and comparisons have been made to assess the enhancement of SRTM vertical accuracy by subtracting DEM raster in Fig. 4(b) and Fig. 4(c) from the reference local DEM in Fig. 4(a) using the raster math tool in GIS application and producing a new raster map which is a DEM showing all the elevations differences (DOD). The results referring to Fig.5 (a) showed that the differences in elevations between LDEM and the SRTM are varying from $+20.61 \mathrm{~m}$ to $-17.87 \mathrm{~m}$ above MSL, while the differences in elevations between LDEM and the scaled SRTM are varying from $+2.99 \mathrm{~m}$ to $-3.09 \mathrm{~m}$ as shown in Fig.5 (b). The RMSEs were computed by using elevations differences (DOD) in Figs.5 (a,b), the results show that RMSE for SRTM was $2.63 \mathrm{~m}$. However, after the enhancement, it decreases to $1.35 \mathrm{~m}$. The achieved enhancement of SRTM vertical accuracy was about $48 \%$ for study region 1 at the Nile delta coast.

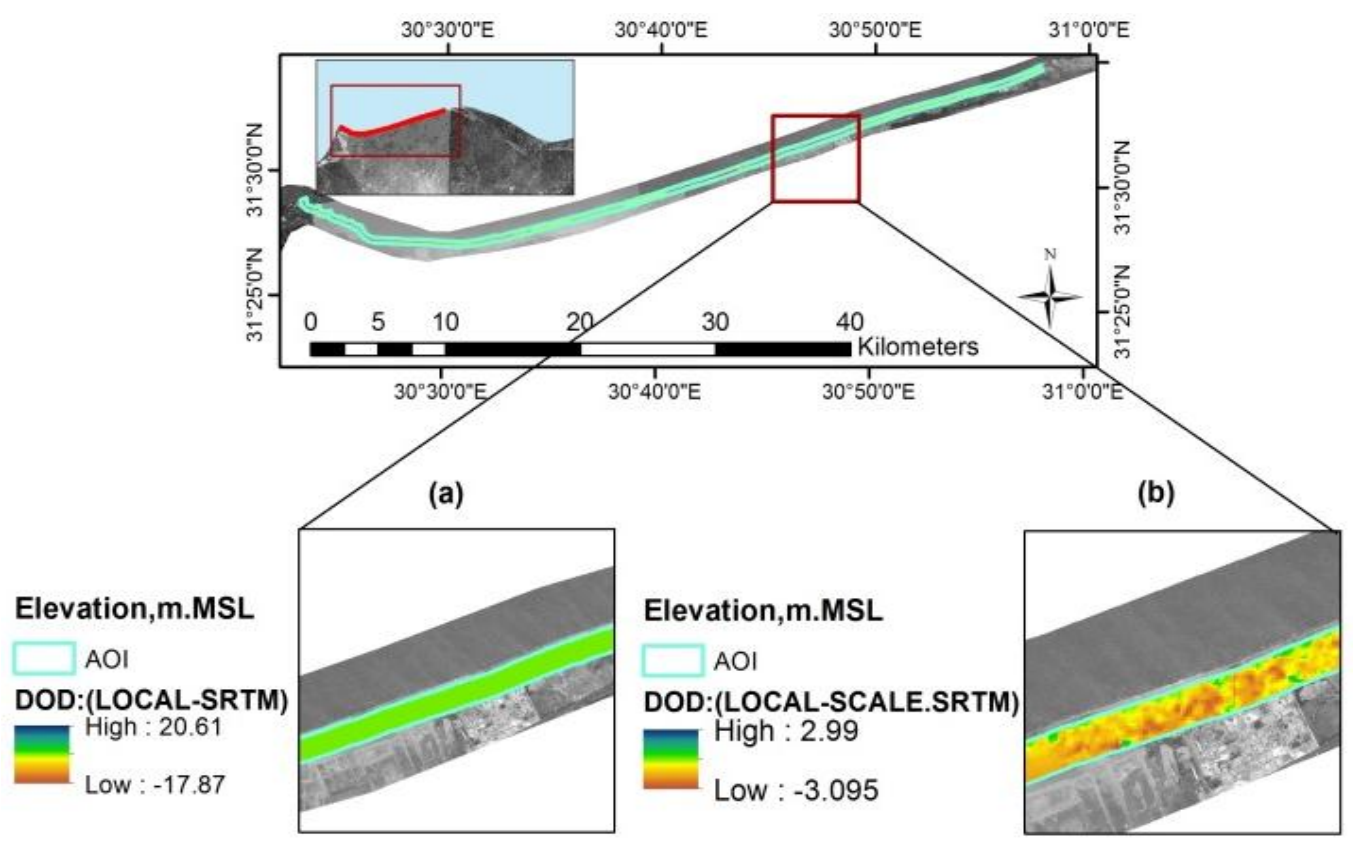

Figure 5. DEM of elevations differences (DOD) (a) Between Local DEM \&SRTM; (b) Between Local DEM \&Scale SRTM DEM for Nile Delta study area

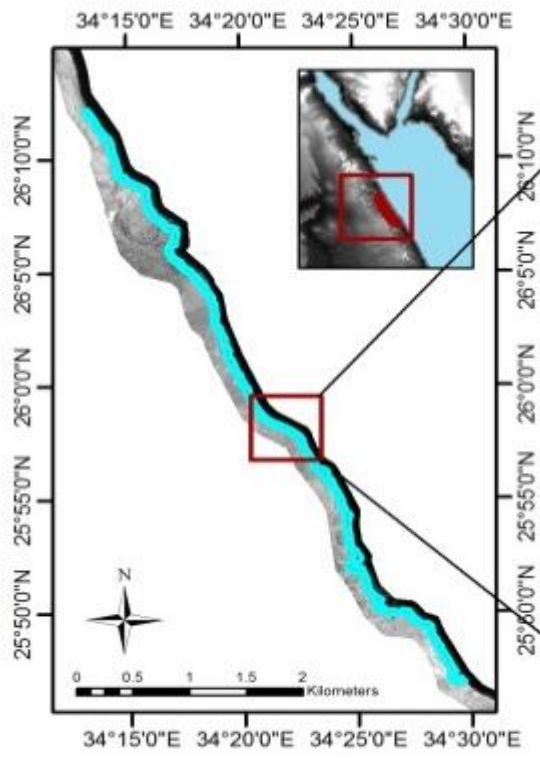

(a)

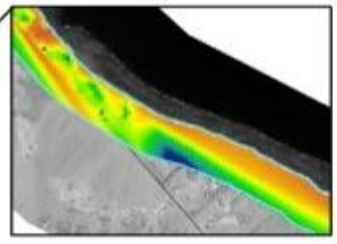

Elevation,m.MSL

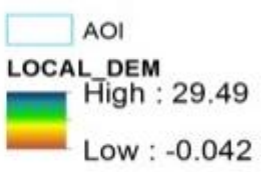

(b)

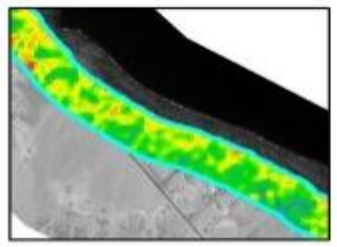

Elevation,m.MSL

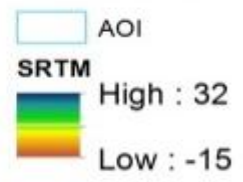

Figure 6. (a) Local DEM; (b) SRTM DEM; (c) Scale SRTM DEM for Red sea coast study area 
The local DEM in Fig.6 (a) for the Red sea coast study area showed variations in elevations from $-0.04 \mathrm{~m}$ to $+29.37 \mathrm{~m}$, while in Fig.6 (b) the variations in elevations were from $-15 \mathrm{~m}$ to $+32 \mathrm{~m}$ for the SRTM. Fig.6(c) showed the enhanced elevation of SRTM from $-3.1 \mathrm{~m}$ to $+15 \mathrm{~m}$ by applying the same formula derived using 46 GCPs in the Red sea coast.

The same-mentioned analysis for the first study region has been used. The results referring to Fig.7 (a) show that the differences in elevations between LDEM and the SRTM vary from $+24.49 \mathrm{~m}$ to $-25.54 \mathrm{~m}$ above MSL, while the differences in elevations between LDEM and the scaled SRTM vary from $+25.50 \mathrm{~m}$ to $-9.70 \mathrm{~m}$ as shown in Fig.7 (b). As well, the RMSEs using elevations differences (DOD) in Fig.7 (a,b) were $5.01 \mathrm{~m}$ for SRTM and decreased after the enhancement to $2.29 \mathrm{~m}$. The SRTM vertical accuracy for the scaled SRTM was improved by about $54 \%$.
The sensitivity of these DEMs to sea-level projections using the recent available local tide gauge data was analysed. Tide records spanned from 2008 to 2018 are used for measuring rates of present-day relative sea-level rise at both tide stations. The annual averages of sea level have been analysed taking with considering the zero-value for mean sea level (MSL) as a datum, it has been found that the MSL at Alexandria, during the period 2008-2018, varies from $41.96 \mathrm{~cm}$ to $45.89 \mathrm{~cm}$ above that datum, with a mean value of $44.76 \mathrm{~cm}$. At Safaga, MSL changes between $47.99 \mathrm{~cm}$ to $53.15 \mathrm{~cm}$, with an average of $51.33 \mathrm{~cm}$. Fig. 8 presents the annual MSL values for both tide gauges. Furthermore, linear regression has been carried out based on this data to compute the rising rates of sea level at the two tide gauge sites. Table 3 presents the obtained trend formulas at both tide gauge stations with their corresponding coefficients of determination.

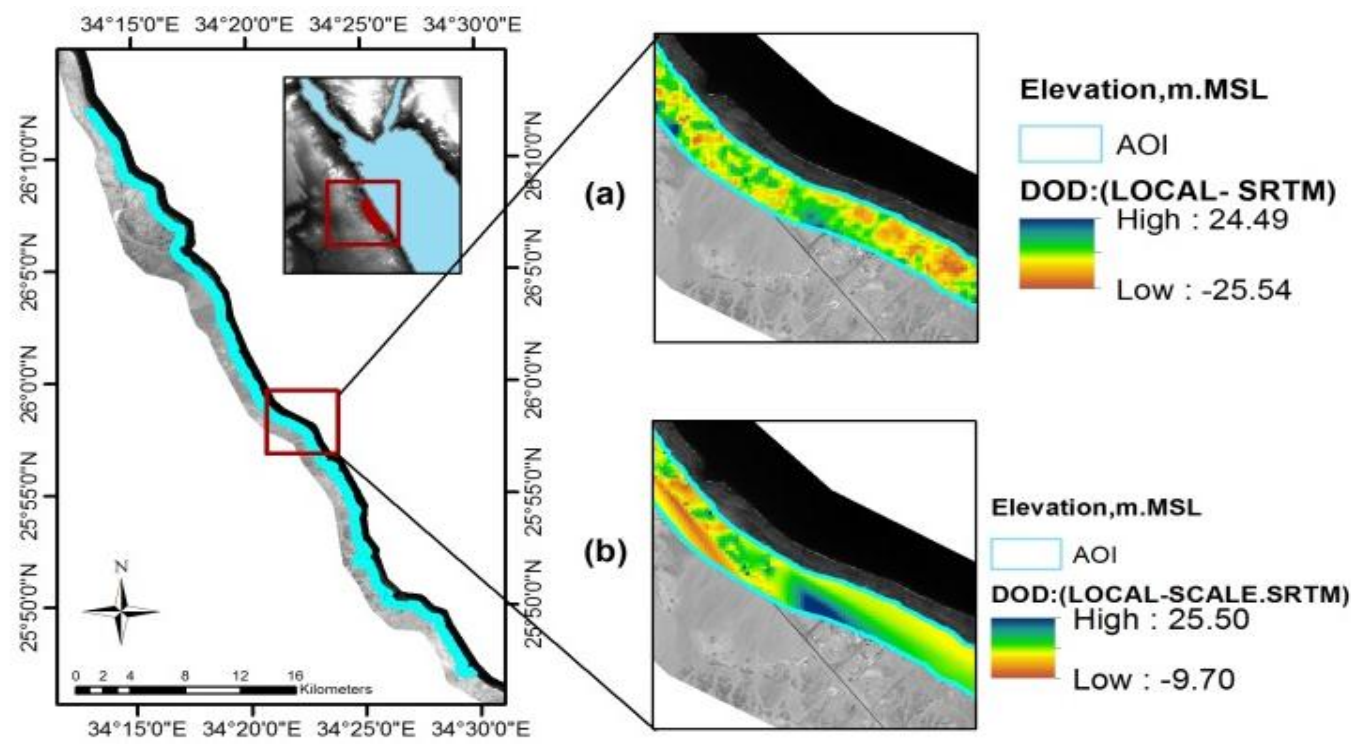

Figure 7. DEM of elevations differences (DOD) (a) Between Local DEM \&SRTM; (b) Between Local DEM \&Scale SRTM DEM for Red sea coast study area

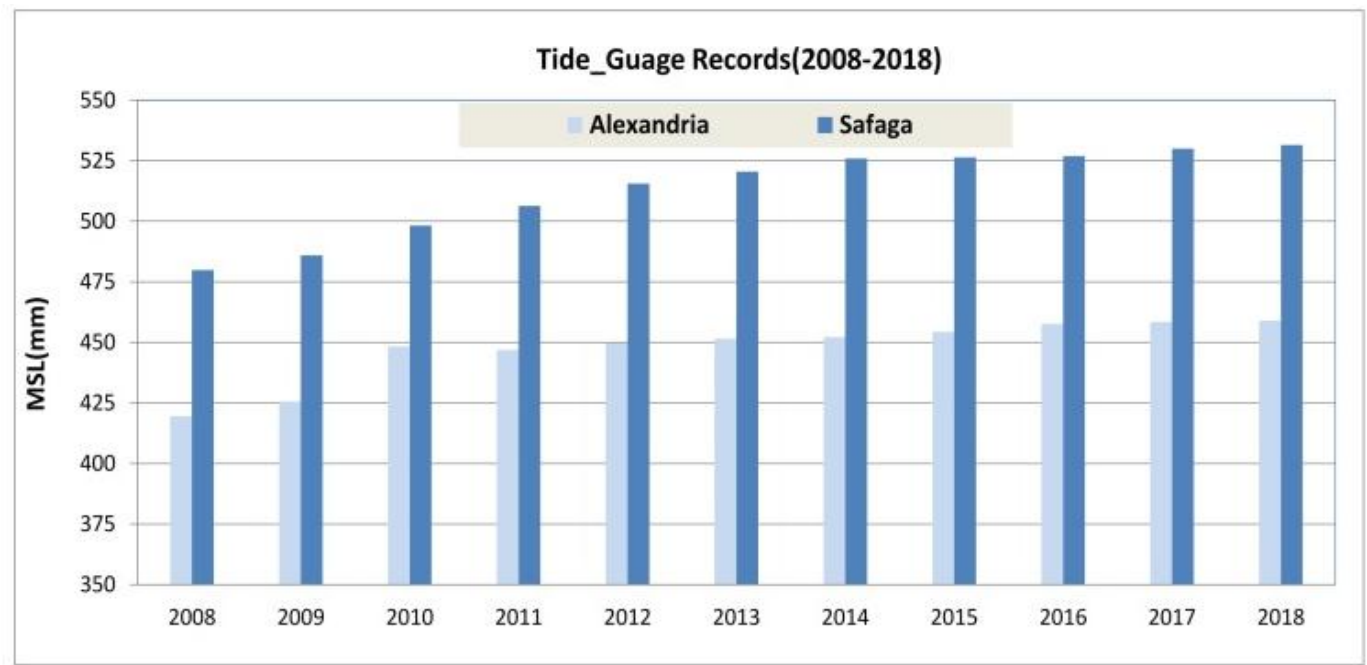

Figure 8. MSL variations at Alexandria and Safaga tide gauges over the Mediterranean and Red Seas 
Table 3. Relative Sea Level Rise at Alexandria and Safaga tide gauges

\begin{tabular}{|c|c|c|}
\hline Tide Station & Sea Rise Trend $(\mathbf{m m})$ & $\mathbf{R}^{\mathbf{2}}$ \\
\hline Alexandria & $\mathrm{MSL}=3.3955 \mathrm{YD}+427.18$ & 0.75 \\
\hline Safaga & $\mathrm{MSL}=5.188 \mathrm{YD}+482.22$ & 0.89 \\
\hline
\end{tabular}

MSL is the value of MSL height in millimeter, and YD is the year difference or number of years since 2008 .

The analyses show that the two locations have positive sea rise trends with significant quality of fitting. These trends indicate that the sea level rising rate of the Mediterranean Sea at Alexandria is $3.4 \mathrm{~mm} / \mathrm{year}$ and in Safaga at the Red Sea is $5.1 \mathrm{~mm} /$ year. Moreover, the data records collected from both stations showed that in the period 2008-2018, the Red Sea level at Safaga is higher than the Mediterranean Sea level at Alexandria. These estimates are close to results of similar previous studies [31.32]. The difference in annual mean sea level value between the Alexandria and Safaga is $7.25 \mathrm{~cm}$ in 2018 .

However, it is worth mentioning that the data utilized in the research are the most recent available local tide records which are consistent with the growing climate change. Hence, it could be considered reliable for long-term MSL rise determination. SLR. planning scenarios for climate adaptation are mostly limited to a time horizon of 100 years. Consequently, the Inundation height at 2100 for the two different terrains using the formulas in Table 3 will be 28 and $43 \mathrm{~cm}$ above the MSL at Alexandria and Safaga, respectively. Most of the low-lying deltas coastlines are subjected to natural subsidence including the Nile delta. However, the red sea coast does not subside, since the subsurface sediments that are made of rocky layers are incompressible. Land subsidence can be estimated using different techniques including the differential interferometric synthetic aperture radar (InSAR) [33]. Based on several recent studies, the average of subsidence rates was calculated as $4 \mathrm{~mm} / \mathrm{y}$ for the study area region1 $[34,35]$. Consequently, the Inundation height values will be approximated to $50 \mathrm{~cm}$ above MSL at the two tide gauge stations by 2100 . There are other certain aspects based on local and global factors that affect coastal flooding and SLR. So, the sensitivity of SRTM DEMs will be examined under another SLR scenario using $1 \mathrm{~m}$ Inundation height. For each scenario specified, the total area of inundation in $\left(\mathrm{km}^{2}\right)$ was calculated with each DEM dataset and the results are given in Table 4. Regarding LDEMS at the flat terrain type of the Nile delta, the percentage of the area inundated at $0.5 \mathrm{~m}$ SLR was increased from $1.5 \%$ to $34.6 \%$ at $1 \mathrm{~m}$ SLR. The inundated areas from SRTM DEM were significantly higher than the local DEM for both scenarios. Also, the scale SRTM didn't show values below $1 \mathrm{~m}$ as detailed and described in Fig.(4,5). The results were so different at the hilly terrain type of the red sea coast. As the percentage of the area inundated for LDEMS were increased from $0.25 \%$ to $1.24 \%$ in both scenarios. Also, the inundated area of the scaled SRTM was enhanced to be $25 \%$ only higher than LDEM in comparison with the SRTM inundated area that was $61 \%$ higher for the $1 \mathrm{~m}$ Inundation height.

\section{Conclusions}

The present study was an attempt to obtain a practical framework for enhancing the vertical accuracy of freely available DEM such as SRTM model at two different terrains along the Egyptian coasts. The proposed methodology was using uniformly distributed GCPs to extract mathematical formulas that can be applied for the enhancement of the SRTM raster DEMs. The RMSE of SRTM data extracted at the reference GCPs concerning plain and hilly regions were $2.88 \mathrm{~m}$ and $5.07 \mathrm{~m}$ respectively. These results match the specified accuracy of SRTM, which is about $\pm 16 \mathrm{~m}$ at a $95 \%$ confidence level [36]. The evaluation of the enhancement results reached $60 \%$ and $45 \%$ at the two terrains of the Nile delta and red sea coasts. The validation process by applying the derived scaled formulas on 60km strip of SRTM raster DEMs ensured that RMSEs were reduced by $48 \%$ to $54 \%$ in comparison with local accurate DEMs at the flat and hilly regions. These results are very well-fitting the obtained ones from the used reference ground control points. With respect to the sensitivity of these DEMs to sea-level projections using the recent local tide gauge data, the scaled SRTM DEM at the red sea region can be reliable as low-cost data with medium accuracy fulfil the requirement of monitoring inundation height response to sea-level rise. However, the accuracy achieved for the enhanced SRTM DEM didn't fit the requirement for coastal inundation studies at the plain area of the Nile delta.

Table 4. Calculated inundated areas in $\left(\mathrm{km}^{2}\right)$ due to sea level rise

\begin{tabular}{|c|c|c|c|c|c|c|}
\hline \multirow{2}{*}{ Inundation height $(\mathrm{m})$} & \multicolumn{3}{|c|}{$\begin{array}{c}\text { Nile Delta coast } \\
\text { Area(1) }=26.72 \mathrm{~km}^{2}\end{array}$} & \multicolumn{3}{|c|}{$\begin{array}{c}\text { Red sea coast } \\
\text { Area }(2)=24.26 \mathrm{~km}^{2}\end{array}$} \\
\hline & $\begin{array}{l}\text { Local } \\
\text { DEM }\end{array}$ & $\begin{array}{l}\text { Scale_ } \\
\text { SRTM }\end{array}$ & SRTM DEM & $\begin{array}{l}\text { Local } \\
\text { DEM }\end{array}$ & $\begin{array}{l}\text { Scale_ } \\
\text { SRTM }\end{array}$ & SRTM DEM \\
\hline 0.5 & 0.396 & 0.000 & 10.719 & 0.061 & 0.445 & 0.744 \\
\hline 1 & 9.247 & 0.000 & 17.977 & 0.310 & 0.468 & 0.789 \\
\hline
\end{tabular}


Therefore, it is concluded that this method approach should be investigated under different mathematical models and parameters to determine the optimal size and distribution of reference ground control points needed to adjust free open DEMs depending on the vertical accuracy demand.

\section{REFERENCES}

[1] Gesch, D. B., "Best practices for elevation-based assessments of sea-level rise and coastal flooding exposure," Frontiers in Earth Science, vol.6, no.230, 2018. DOI:10.3389/feart.2018.00230.

[2] Sorensen, R., Seibert, J., "Effects of DEM Resolution on the Calculation of topographical indices: TWI and Its Components," Journal of Hydrology, vol. 347, no. 1-2, pp. 79-89, 2007. DOI:10.1016/j.jhydrol.2007.09.001

[3] Pachauri, R. K., Allen, M. R., Barros, V. R., Broome, J., Cramer, W., Christ, R., ... \& van Ypserle, J. P.," Climate Change 2014: Synthesis Report. Contribution of Working Groups I, II and III to the Fifth Assessment Report of the Intergovernmental Panel on Climate Change," IPCC, pp.1-151, 2014.

[4] Croneborg, L., Saito, K., Matera, M., McKeown, D., \& van Aardt, J., "Digital Elevation Models: A Guidance Note on How Digital Elevation Models are Created and Used-Includes Key Definitions, Sample Terms of Reference, and How Best to Plan a DEM-Mission", World Bank, Washington, 2020. URL: http://hdl.handle.net/10986/34445 p://hdl.handle.net/10986/34445

[5] Shaharizuan, H. A. R. I. Z., "Surveying with photogrammetric Unmanned Aerial Vehicles (UAV)-An industrial breakthrough," In Watt Malaysia exhibition and conference, vol.10, April, 2019.

[6] li, Xinchuan, Zhang, Youjing, Jin, Xiuliang, Qiaoning, He \& Zhang, Xiuping., "Comparison of digital elevation models and relevant derived attributes," Journal of Applied Remote Sensing, vol. 11, no.4, pp.1-23, 2017. DOI: 11. 1. 10.1117/1.JRS.11.046027.

[7] Abrams, M., Tsu, H., Hulley, G., Iwao, K., Pieri, D., Cudahy, T., \& Kargel, J., "The advanced spaceborne thermal emission and reflection radiometer (ASTER) after fifteen years: review of global products," International Journal of Applied Earth Observation and Geoinformation, vol.38, pp. 292-301, 2015.

[8] Tachikawa, T., Kaku, M., Iwasaki, A., Gesch, D. B., Oimoen, M. J., Zhang, Z., ... \& Carabajal, C., "ASTER Global Digital Elevation Model Version 2-Summary of Validation Results," NASA, 2011.

[9] Yap, L., Kandé, L. H., Nouayou, R., Kamguia, J., Ngouh, N. A., \& Makuate, M. B., "Vertical accuracy evaluation of freely available latest high-resolution $(30 \mathrm{~m})$ global digital elevation models over Cameroon (Central Africa) with GPS/leveling ground control points," International Journal of Digital Earth, vol.12, no. 5, pp. 500-524, 2019.

[10] Mukul, M., Srivastava, V., \& Mukul, M., “Analysis of the accuracy of shuttle radar topography mission (SRTM) height models using international global navigation satellite system service (IGS) network," Journal of Earth System Science, vol.124, no.6, pp.1343-1357, 2015. DOI: https://doi.org /10.1007/s12040-015-0597-2

[11] Luana, S., Hou, X., \& Wang, Y., “Assessing the accuracy of SRTM dem and Aster Gdem datasets for the coastal zone of Shandong Province, Eastern China," Polish Maritime Research, vol. 22, pp.15-20, 2015. DOI: https://doi.org/10.1 515/pomr-2015-0026

[12] Farr, T. G., Rosen, P. A., Caro, E., Crippen, R., Duren, R., Hensley, S., \& Seal, D., "The shuttle radar topography mission," Review of geophysics, vol.45, no.2, 2007. DOI: https://doi.org/10.1029/2005RG000183

[13] Robinson, N., Regetz, J. \& Robert, G., "EarthEnv-DEM90: A nearly-global, void-free, multi-scale smoothed, $90 \mathrm{~m}$ digital elevation model from fused ASTER and SRTM data," ISPRS Journal of Photogrammetry and Remote Sensing, vol.87, pp.57-67, 2014.DOI:10.1016/j.isprsjprs.2013.11.002.

[14] Danielson, J. J., and D. B. Gesch, "Global Multi-resolution Terrain Elevation Data 2010 (GMTED2010)," U.S. Geol. Surv, Open File Report 2011-1073, pp.1-26, 2011. URL: https://pubs.usgs.gov/of/2011/1073/

[15] Carabajal, C. C., Harding, D. J., Boy, J. P., Danielson, J. J., Gesch, D. B., \& Suchdeo, V. P., "Evaluation of the global multi-resolution terrain elevation data 2010 (GMTED2010) using ICESat geodetic control. In International Symposium on Lidar and Radar Mapping 2011: Technologies and Applications," International Society for Optics and Photonics, vol.8286, October, 2011. https://doi.org/10.1117/ 12.912776

[16] Earth Resources Observation and Science (EROS) Center, "USGS EROS Archive-Digital Elevation- Global 30 Arc-Second Elevation (GTOPO30).", USGS, DOI:/10.5066/F7DF6PQS (accessed Mar. 28, 2021).

[17] Mukherjee, S., Joshi, P., Mukherjee, S., Ghosh, A., Garg, R. \& Mukhopadhyay, A., "Evaluation of vertical accuracy of open source Digital Elevation Model (DEM)," International Journal of Applied Earth Observation and Geoinformation, vol.21, pp.205-217, 2013. DOI:10.1016/j.jag.2012.09.004.

[18] Shawky, M., Moussa, A., Hassan, Q. K., \& El-Sheimy, N., "Pixel-Based Geometric Assessment of Channel Networks/Orders Derived from Global Spaceborne Digital Elevation Models,” Remote Sensing, vol.11, no. 235, 2019. DOI: https://doi.org/10.3390/rs11030235

[19] Heliani, L. S., "Evaluation of global geopotential model and its application on local geoid modelling of Java Island, Indonesia," AIP Conference Proceedings, AIP Publishing, vol. 1755, no. 1, p. 100005, July, 2016.

[20] Milbert, D. G., \& Smith, D. A., "Converting GPS height into NAVD88 elevation with the GEOID96 geoid height model," In GIS LIS-INTERNATIONAL CONFERENCE, vol. 1, pp. 681-692, November 1996.

[21] Falchi, U., Parente, C., \& Prezioso, G., "Global geoid adjustment on local area for GIS applications using GNSS permanent station coordinates," Geodesy and Cartography, vol. 44, no.3, pp. 80-88, 2018.

[22] Rabah, M., El-Hattab, A., \& Abdallah, M., “Assessment of 
the most recent satellite based digital elevation models of Egypt," NRIAG journal of astronomy and geophysics, vol. 6, no.2, pp.326-335, 2017.

[23] El-Quilish, M., El-Ashquer, M., Dawod, G., \& El Fiky, G., "Development and Accuracy Assessment of High-Resolution Digital Elevation Model Using GIS Approaches for the Nile Delta Region, Egypt," American Journal of Geographic Information System, vol.7, no.4, pp.107-117, 2018. DOI: 10.5923/j.ajgis.20180704.02

[24] Al-Krargy, E. M., Hosny, M. M., \& Dawod, G. M., "Investigating the precision of recent global geoid models and global digital elevation models for geoid modelling in Egypt," RN, vol.4, no.1, 2015.

[25] Mousavi, M. E., Irish, J. L., Frey, A. E., Olivera, F., \& Edge, B. L., "Global warming and hurricanes: the potential impact of hurricane intensification and sea level rise on coastal flooding," Climatic Change, vol.104, no.3-4, pp. 575-597, 2011.

[26]Zhang, K., Gann, D., Ross, M., Robertson, Q., Sarmiento, J., Santana, S., ... \& Fritz, C.," Accuracy assessment of ASTER, SRTM, ALOS, and TDX DEMs for Hispaniola and implications for mapping vulnerability to coastalflooding," Remote Sensing of Environment, vol.225, pp.290-306,2019.

[27] Van de Sande, B., Lansen, J., \& Hoyng, C., "Sensitivity of coastal flood risk assessments to digital elevation models. Water," vol.4, no.3, pp.568-579, 2012.

[28]Egyptian Environmental Affairs Agency (EEAA), "Integrated Coastal Zones Management (ICZM)," URL:http://www.eeaa.gov.eg/enus/topics/management/iczm .aspx. (accessed Mar. 28, 2021).

[29] Patel A., Katiyar S.K. and Prasad V., "Performances evaluation of different open source DEM using Differential
Global Positioning System (DGPS)," Egyptian J. Remote Sens, Space Sci., vol.19, pp.7-16, 2016.

[30] Ince, E. S., Barthelmes, F., Reißland, S., Elger, K., Förste, C., Flechtner, F., Schuh, H., "ICGEM - 15 years of successful collection and distribution of global gravitational models, associated services and future plans," Earth System Science Data, vol.11, pp. 647-674, 2019. DOI: http://doi.org/10.519 4/essd-11-647-2019

[31] Sharaf El-Din, S. H., Eid, F. M., \& Alam El-Din, K. A., "Effect of weather system on the regime of sea level variations along the Suez Canal," In The First International Conference on the Mediterranean Coastal Environment, MEDCOAST, vol. 93, pp. 2-5, November, 1993.

[32] Frihy, O. E., "Sea-level rise and shoreline retreat of the Nile delta promontories, Egypt," Natural Hazards, vol.5, no.1, pp. 65-81, 1992.

[33] Yanyan Agustian, Fuad Hasan, Raden Herdian Bayu Ash Siddiq, "Land Subsidence of Kanto Plain Detection Using JERS-1 SAR Interferometry," Civil Engineering and Architecture, Vol. 7, No. 3A, pp. 65 - 69, 2019. DOI: 10.13189/cea.2019.071309.

[34] Stanley, J.D., Clemente, P.L., "Increased land subsidence and sea-level rise are submerging Egypt's Nile Delta coastal margin," GSA Today, vol.27, no.5, pp. 4-11, 2017.

[35] Rateb, A., \& Abotalib, A. Z., "Inferencing the land subsidence in the Nile Delta using Sentinel-1 satellites and GPS between 2015 and 2019," Science of The Total Environment, vol.729, no.138868, 2020.

[36] Miliaresis, G. C., \& Paraschou, C. V., "Vertical accuracy of the SRTM DTED level 1 of Crete," International Journal of Applied Earth Observation and Geoinformation, vol.7, No. 1, pp. 49-59, 2005. 